\title{
IDENTIFIKASI JENIS TUMBUHAN BAWAH YANG BERKHASIAT OBAT DI KAWASAN ARBORETUM SYLVA UNIVERSITAS TANJUNGPURA
}

\author{
(Identification of Medicinal Plants from Understorey Plants at Arboretum Sylva Universitas \\ Tanjungpura)
}

\author{
Yohanes Ason, Farah Diba, M. Sofwan Anwari \\ Fakultas Kehutanan Universitas Tanjungpura. Jln Imam Bonjol Pontianak 78124 \\ E-mail: asonsylva@gmail.com
}

\begin{abstract}
Understorey plants has many function, beside for the ornamental plants, it also has a function for medicinal plants. The research aimed to exploration understorey plant in Arboretum Sylva Universitas Tanjungpura and identification the understorey plants as medicinal plant. Arboretum Sylva Universitas Tanjungpura was located in the central of Pontianak City with average area around 3.2 hectares. The methods for exploration and identification the understorey plants were with inventory methods in all area of arboretum. The plant was collected and identification the used of plant to medicine was conduct by in depth interview with the person who has used the plants and from references of literature. The result of research found 23 understorey plants and divided into 19 families. The understorey plants which has a function for medicinal plants consist of Imperata cylindrica, Asplenium nidus, Lophatherum gracile, Stenochlaena palustris, Piper aduncum Lim, Melastoma malabathricum, Mimosa pudica, Ageratum conyzoides, Pyrrosia piloselloides, Justicia gendarussa, Cordyline fruiticosa, Sansevieria trifasciata, Manihot esculenta, Capsicum frutescens, Nymphaea alba, Ananas comosus, Euphorbia tithymaloides, Phyllanthus urinaria, Saccharum officinarum, Alpinia galanga, Aloe vera, Piper ningrum and Pandanus amaryllifolius. The families of understorey plants consist of Poaceace, Aspleniaceae, Blechnaceae, Piperaceace, Melastomaceae, Fabaceae, Asteraceae, Polypodiaceae, Acanthaceae, Asparagaceae, Ruscaceae, Euphorbiaceae, Solanaceae, Nymphaeaceae, Bromeliaceae, Phyllanthaceae, Zingiberaceae, Xanthorrhoeaceae, and Pandanaceae. The plants use to overcome the fever, headache, reduce high blood pressure, and anti-inflamation.
\end{abstract}

Keyword: Arboretum Sylva, fever, medicinal plants, understorey plants, Zingiberaceae

\section{PENDAHULUAN}

Indonesia kaya akan sumber bahan obat alam yang telah digunakan oleh sebagian besar rakyat Indonesia secara turun temurun, maka perlu didorong upaya pengenalan, penelitian, pengujian dan pengembangan khasiat dan kegunaan suatu tanaman obat (Wijayakusuma, dkk 1993). Tumbuhan bawah memiliki berbagai manfaat, salah satunya sebagai tanaman obat. Komposisi dan keanekargaman tumbuhan bawah ikut menentukan struktur hewan yang pada akhirnya akan berpengaruh pada fungsi ekologi hutan. Tumbuhan bawah merupakan sumber kekayaan plasma nutfah yang harus dilestarikan, dipelajari, dimanfaatkan. Tanaman obat yang beranekaragam 
jenis, habitus, dan khasiatnya mempunyai peluang besar serta memberi kontribusi bagi pembangunan dan pengembangan hutan.

Menurut Departemen Kesehatan Republik Indonesia, definisi tanaman obat Indonesia tercantum dalam SK Menkes No.149/SK/Menkes/IV/1978 adalah sebagai berikut:

a. Tanaman atau bagian tanaman yang digunakan sebagai bahan obat atau jamu.

b. Tanaman atau bagian tanaman yang digunakan sebagai bahan pemula bahan baku obat.

c. Tanaman atau bagian tanaman yang diekstraksi dan ekstrak tanaman tersebut digunakan sebagai obat.

Identifikasi bertujuan untuk mengetahui morfologi suatu tumbuhan dengan menganalisis ciri-ciri morfologi (generatif maupun vegetatif) secara detail pada semua jenis tumbuhan. Melakukan identifikasi berarti mengungkapkan atau menetapkan jati diri suatu spesies yang dalam hal ini menentukan namanya dan tempatnya yang benar dalam klasifikasi. Identifikasi adalah proses pengenalan, menempatkan objek atau individu dalam suatu kelas sesuai dengan karakteristik tertentu. Untuk istilah identifikasi sering juga disebut dengan istilah determinasi yang diambil dari bahasa Belanda Determinatie atau penentuan.

Kegiatan pengenalan jenis tumbuhan pada saat di lapangan ada beberapa sifat yang harus dijadikan ciri penentu. Sifat-sifat tersebut dikelompokan menjadi sifat-sifat botanis, baik dengan sifat vegetatif atau generatif dan sifat satu dengan yang lainnya saling menunjang. Salah satu contoh pengenalan satu jenis tumbuhan, sifat-sifat botanis seperti bunga dan buah tidak selalu ada pada setiap saat, akan tetapi sifat lainnya selalu ada seperti pada daun, kulit, batang, getah, percabangan, ranting, akar dan warna kulit (Ambriansyah, 2010).

Tujuan dari penelitian untuk mengetahui jenis-jenis tumbuhan bawah yang berkhasiat obat di kawasan Arboretum Sylva Indonesia Fakultas Kehutanan Universitas Tanjungpura. Manfaat penelitian untuk memberikan data dan informasi mengenai jenis-jenis tumbuhan bawah yang berkhasiat obat di kawasan Arboretum Sylva Indonesia Fakultas Kehutanan Universitas Tanjungpura, sehingga dapat menjadi acuan dalam upaya pelestarian tumbuhan.

\section{METODE PENELITIAN}

Penelitian dilaksanakan pada kawasan Arboretum Sylva Indonesia Fakultas Kehutanan Universitas Tanjungpura dengan waktu pelaksanaan penelitian pada bulan Desember 2016 sampai Januari 2017. Objek penelitian adalah semua jenis tumbuhan bawah yang berkhasiat obat, yang terdapat pada lokasi penelitian. Metode penelitian yang digunakan adalah dengan menggunakan metode eksplorasi flora yang dilakukan dengan cara jelajah, yaitu dengan menjelajahi setiap sudut lokasi di kawasan yang diteliti (Rugayah dkk, 2004). Inventarisasi dilakukan terhadap semua jenis tumbuhan bawah yang berkhasiat obat 
yang dijumpai di lokasi penelitian. Selanjutnya dilakukan identifikasi terhadap tumbuhan bawah yang ditemukan dan cara pemanfaatan tumbuhan bawah sebagai obat.

\section{HASIL DAN PEMBAHASAN}

Berdasarkan hasil pengamatan di lapangan dengan menggunakan metode eksplorasi ditemukan 23 jenis tumbuhan bawah berkhasiat obat yang tergolong dalam 19 famili. Nama-nama jenis tumbuhan bawah yang berkhasiat obat yang ditemukan pada lokasi penelitian disajikan pada Tabel 1.

Tabel 1. Tumbuhan bawah yang berkhasiat obat di kawasan Arboretum Sylva Universitas Tanjungpura (Understorey plants which has a function as medicinal plants at Arboretum Sylva Universitas Tanjungpura)

\begin{tabular}{clll}
\hline No & Famili & Nama Ilmiah & Nama Lokal \\
\hline 1. & Poaceace & Imperata cylindrica & Alang-alang \\
2. & Aspleniaceae & Asplenium nidus & Pakis sarang burung \\
3. & Poaceace & Lophatherum gracile & Rumput Bambu \\
4. & Blechnaceae & Stenochlaena palustris & Pakis Lemiding \\
5. & Piperaceace & Piper aduncum Lim & Sirih Hutan \\
6. & Melastomaceae & Melastoma malabathricum & Cengkodok \\
7. & Fabaceae & Mimosa pudica & Putri Malu \\
8. & Asteraceae & Ageratum conyzoides & Bandotan \\
9. & Polypodiaceae & Pyrrosia piloselloides & Sisik naga \\
10. & Acanthaceae & Justicia gendarussa & Gandarusa \\
11. & Asparagaceae & Cordyline fruiticosa & Andong \\
12. & Ruscaceae & Sansevieria trifasciata & Lidah Mertua \\
13. & Euphorbiaceae & Manihot esculenta & Ubi Kayu \\
14. & Solanaceae & Capsicum frutescens & Cabe Rawit \\
15. & Nymphaeaceae & Nymphaea alba & Teratai putih \\
16. & Bromeliaceae & Ananas comosus & Nanas \\
17. & Euphorbiaceae & Euphorbia tithymaloides & Pokok Lipan \\
18. & Phyllanthaceae & Phyllanthus urinaria & Meniran \\
19. & Poaceae & Saccharum officinarum & Tebu \\
20. & Zingiberaceae & Alpinia galanga & Lengkuas \\
21. & Xanthorrhoeaceae & Aloe vera & Lidah buaya \\
22. & Piperaceae & Piper nigrum & Lada \\
23. & Pandanaceae & Pandanus amaryllifolius & Pandan \\
\hline
\end{tabular}

Pemanfaatan tumbuhan bawah sebagai bahan obat diuraikan sebagai berikut:

\section{Alang-alang (Imperata cylindrica)}

Pemanfaatan

Penyakit yang biasa diobati adalah menyuburkan dan menghitamkan rambut, demam, mimisan, gangguan ginjal, peluruh kencing, dan darah tinggi.

\section{Cara Penggunaan}

a. Tumbuk halus akar alang-alang sebanyak15-20 g, rebus hingga mendidih. Air rebusan digunakan untuk membasuh kepala1-2 kali sehari untuk menyuburkan rambut atau diminum segelas sehari untuk meredakan demem.

b. Tumbuk akar alang-alang segar secukupnya lalu diperas. Saring air 
perasannya kira-kira $100 \mathrm{ml}$ dan minum satu kali sehari untuk yang mengalami mimisan.

c. Rebus akar alang-alang segar sebanyak 10 g dengan 3 gelas air sampai tersisa 1 gelas. Setelah dingin, disaring. Minum sekaligus sebagai peluruh kencing.

\section{Pakis sarang burung}

\section{Pemanfaatan}

Manfaat pakis sarang burung yaitu untuk mengobati bengkak, luka memar, menyuburkan rambut, demam, sakit kepala, kontrasepsi, gigitan atau sengatan hewan berbisa, anti radang dan pelancar peredaran darah.

\section{Cara Penggunaan}

a. Daun pakis sarang burung segar sebanyak 15 g dicuci dan direbus dengan $200 \mathrm{ml}$ air sampai mendidih selama 15 menit, didinginkan dan saring. Hasil saringan diminum sekaligus dan melakukan pengobatan sebanyak 2 kali sehari, pagi dan sore.

b. Daun pakis sarang burung segar sebanyak $15 \mathrm{~g}$, dicuci, ditumbuk halus dan ditambahkan sedikit anggur kemudian diborehkan ke bagian yang sakit.

c. Daun pakis sarang burung ditumbuk dan dicampur dengan parutan kelapa kemudian dioleskan pada rambut.

\section{Rumput Bambu}

\section{Pemanfaatan}

Manfaat rumput bambu yaitu mengobati gusi bengkak, menghentikan pendarahan yang terjadi karena mimisan, sariawan, menurunkan demam, mengobati campak, influenza, kencing tidak lancer, kencing berdarah (hermaturia), meredakan nyeri, sakit tenggorokan, mempermudah proses persalinan.

\section{Cara Penggunaan}

Untuk memanfaatkan tumbuhan tersebut sebagai obat alami tradisional adalah dengan cara merebus daun sebanyak 10 - 15 gram dengan 3 gelas air hingga mendidih dan menyisakan 1 gelas air saja. Minum air rebusan ini dalam 1 hari cukup sekali saja. Lakukan setiap hari hingga gejala penyakit hilang.

\section{Pakis Lemiding}

Pemanfaatan

Untuk mengobati anemia, meningkatkan kualitas air susu ibu (ASI).

Cara Penggunaan

Daun diolah menjadi masakan dan dimakan.

\section{Sirih Hutan}

\section{Pemanfaatan}

a. Untuk mengobati batuk menahun

b. Untuk penghilang bau badan

c. Untuk sari rapet, keputihan dan untuk menjaga kesehatan kelamin wanita

d. Sebagai obat kumur sariawan, radang mulut, sakit gigi

e. Sebagai obat kulit untuk sakit gatalgatal, koreng, luka, jerawat, alaergi/biduran

f. Untuk pengobatan sakit asma, bronkitis

g. Untuk mengobati sakit jantung dan wasir

Cara Penggunaan

a. Siapkan tiga lembar daun sirih hutan dan seduhkan pada satu gelas air panas. Setelah air sudah hangat gunakanlah untuk berkumur dengan 
posisi kepala melihat keatas. Beberapa debit air harus masuk ke dalam tenggorokan hingga pangkalnya. Lakukan secara rutin sampai radang tenggorokan sembuh.

b. Sediakan tujuh lembar daun sirih hutan dan juga satu sendok teh lada putih. Lalu gerus dua bahan tersebut hingga halus. Kemudian campurkan bahan yang dihaluskan tadi dengan minyak kayu putih secukupnya saja. Gunakan obat alami ini pada leher dan juga dada dengan berbaring.

c. Sediakan enam lembar daun sirih hutan segar dan potong kecil-kecil. Lalu rebus pada panci berisi dua gelas air dan tambahkan gula sedikit saja. Tunggu hingga air menyusut menjadi setengahnya dan tuang kedalam gelas. Saring hasil rebusannya dan minum sebanyak tiga sendok makan tiga kali sehari.

d. Sediakan daun sirih hutan secukupnya dan rebus pada dua gelas air sampai menyusut menjadi satu gelas saja. Gunakanlah hasil rebusan daun sirih hutan tersebut untuk berkumur hingga sakit gigi reda.

e. Siapkan tiga lembar daun sirih hutan segar yang sudah dicuci bersih. Kemudian rebus hingga layu dan lumatkan hasil rebusan. Kemudian tempelkan pada bibir atau lidah yang terkena sariawan. Lakukan secara rutin makasariawan akan sembuh.

f. Tumbuk daun sirih hutan yang sudah bersih secukupna saja, lalu seduh pada satu gelas air panas. Setelah air hangat gunakanlah untuk membasuh wajah. Lakukan sebanyak dua kali sehari secara rutin hingga jerawat hilang.

g. Siapkan sepuluh lembar sirih hutan segar yang sudah dibersihkan. Rebus kedalam satu setengah liter air sampai mendidih. Tunggu hingga rebusan menjadi hangat. Kemudian gunakan hasil rebusan tersebut untuk membersihkan area kewanitaan.

h. Balurkan daun sirih hutan yang sudah dilumatkan pada kulit yang dirasa gatal. Lalu balut dengan kain bersih yang telah dibasahi dengan air hangat, tunggu hingga gatal pada kulit reda.

\section{Cengkodok}

\section{Pemanfaatan}

Penyakit yang bias diobati adalah diare, disentri, tonikum, keputihan, setelah bersalin, luka, wasir, penetral racun, dan sakit gigi.

\section{Cara Penggunaan}

a. Keringkan daun kemudian rebus bersama jahe, gula, dan bangle. Minum setelah hangat untuk mengatasi keputihan, diare, disentri dan sebagai tonikum.

b. Kunyah daun hingga lumat, lalu ditampalkan pada lukauntuk menghentikan pendarahan.

c. Potong akar sebesar jari kelingking dan rebus dengan tiga gelas air hingga tersisa satu gelas, kemudian diminum untuk mengobati wasir.

d. Rebus daun sebanyak $60 \mathrm{~g}$ dengan air sebanyak tiga gelas sampai tersisa satu gelas. Setelah itu, saring dan dinginkan kemudian minum sampai habis untuk menetralkan racun.

e. Remas daun menggunakan tangan dan dibalurkan pada gigi yang sakit. 


\section{Putri Malu}

\section{Pemanfaatan}

Untuk mencegah dan mengobati penyakit hepatitis, penyakit paru-paru, menyembuhkan rematik, susah tidur (Insomnia), batuk berdahak.

\section{Cara Penggunaan}

a. Tanaman putri malu bermanfaat untuk mencegah dan mengobati penyakit hepatitis. Caranya dengan merebus putri malu sebanyak 10 gram dengan air 200 cc sampai mendidihselama 15 menit. Hasil rebusan diminum rutin.

b. Bronchitis Kronik merupakan salah satu penyakit paru-paru. Bagi yang punya penyakit, bisa merebus 60 gram akar putri malu dengan sebanyak 600 cc air, direbus dengan api kecil sehingga menjdi $200 \mathrm{cc}$. Lalu air dibagi untuk dua kali minum. Mimosa pudica 30 gram, akar peristrophe roxburghiana 10 gram, keduanya direbus, dibagi menjadi 2 dosis/hari.

c. Menyembuhkan rematik. Cara penggunaannya yaitu, 15 gram akar putri malu direndam dalam arak putih 500 cc selama 2 minggu. Kemudian ditempelkan di tempat yang sakit.

d. Susah tidur (Insomnia). Bagi orang yang menderita susah tidur, bias mencoba untuk merebus sebanyak 30-60 gram daun putri malu dan diminum airnya. Rasanya mungkin lebih enak kalau mencampur 15 gram daun putri malu dengan 15 gram daun sawi langit (Vemonia cinerea) dan 30 gram daun calincing lalu direbus dan airnya kemudian diminum.

e. Batuk berdahak. Tanaman ini juga berkhasiat untuk yang sedang batuk apalagi yang banyak dahaknya. Caranya rebus akar putri malu sebanyak 10-15 gram lalu airnya diminum.

\section{Bandotan}

\section{Pemanfaatan}

Digunakan untuk mengobati disentri, diare, dan luka.

\section{Cara Penggunaan}

a. Akar sebanyak $30 \mathrm{~g}$ direbus dengan $600 \mathrm{cc}$ air hingga tersisa $300 \mathrm{cc}$, disaring dan diminum airnya selagi hangat untuk mengatasi disentri, diare, atau panas.

b. Akar ditumbuk lalu dioleskan pada bagian yang terkena luka senjata tajam.

c. Daun ditumbuk halus untuk sakit dada dan luka atau dibalurkan untuk sakit perut atau diare.

\section{Sisik Naga}

\section{Pemanfaatan}

Beberapa indikasi pengobatan yang bisa dilakukan oleh sisik naga meliputi : TBC kulit dengan pembesaran kelenjar getah bening, sakit kuning, gondongan, disentri, susah buang air besar, sakit perut,radang gusi, sariawan, batuk, abses paru-paru, TB paru yang disertai dengan batuk berdarah, kencing nanah, rematik, pendarahan, seperti luka berdarah, mimisan, berak darah, muntah darah atau pendarahan pada perempuan, dan kanker payudara.

\section{Cara Penggunaan}

a. Untuk mengobati sakit kuning. Daun sisik naga 15-30 g dicuci bersih 
kemudian direbus dalam 3 gelas air sampai airnya tersisa setengah. Setelah dingin, saring dan air saringannya diminum $1 / 2$ gelas. Lakukan sebanyak 3 kali dalam sehari.

b. Untuk mengobati sariawan. Cuci daun sisik naga sebanyak 1 genggam sampai bersih kemudian direbus dengan 2 gelas air sampai mendidih. Kemudian gunakan air saringan tersebut untuk berkumur selagi hangat.

c. Menghentikan proses pendarahan. Caranya menggiling sekitar 30 gram daun sisik naga sampai halus. Hasil gilingan tersebut diperas dan disaring, kemudian airnya diminum. Lakukan hal tersebut sampai 3 kali dalam sehari sampai sembuh.

d. Cuci 15-30 g daun sisik naga segar, lalu rebus dalam 3 gelas air smpai tersisa 1 gelas. Setelah dingin, saring dan air saringannya diminum, sehari 2 kali, masing-masing $1 / 2$ gelas.

\section{Gandarusa}

\section{Pemanfaatan}

Penyakit yang bisa diobati yaitu sakit kepala, rematik, patah tulang, memar, keseleo, mual, haid tidak teratur.

\section{Cara Penggunan}

a. Sakit kepala. Daun gandarusa yang segar sebnyak 15 gram, 1 sendok the lada, dan 15 gram jahe, semuanya ditumbuk bersama-sama. Tambahkan 1 sendok makan minyak kayu putih. Campuran itu gosokan di leher dan punggung.

b. Rematik. Daun gandarusa yang segar sebanyak 30-60 gram, atau daun yang kering sebanyak 15-30 gram, direbus. Kemudian minum air rebusannya.

c. Patah tulang. Daun gandarusa yang segar dilumatkan, atau daun kering dihaluskan. Kemudian diaduk dengan arak, cuka secukupnya, digunakan untuk kompres. Pastikan tulang patah dalam posisi yang benar dan terfiksasi.

d. Memar dan keseleo. Daun gandarusa diolesi minyak, lalu layukan diatas api. Tempelkan dibagin yang terasa sakit. Atau ramuan lain, daun gandarusa segarsebanyak 30-60 gram atau daun kering15-30 gram, direbus dan diminum air rebusannya.

e. Mual. Ambil 50 gram daun gandarusa yang segar, lalu dicuci dan dijus bersama 1 buah jeruk manis atau 1 buah apel. Campur dengan sedikit air tanpa es, agar tidak membuat kembung.

f. Haid tidak teratur. Daun gandarusa sebanyak 50 gram, dan 5 butir lada putih dicuci, ditumbuk, disaring. Tambahkan satu sendok madu pada air perasannya, lalu minum.

\section{Andong}

Pemanfaatan

Tanaman ini bisa dimanfaatkan untuk TBC paru disertai batuk darah

\section{Cara Penggunaan}

Cara penggunaannya, bagian tanaman berupa daun kering 15-30 gram, atau bunga kering 9-15 gram atau akar kering 6-10 gram, yang direbus selanjutnya diminum.

\section{Lidah Mertua}

\section{Pemanfaatan}

Penyakit yang bisa diobati adalah batuk, diabetes, dan ambeien. 


\section{Cara Penggunan}

a. Serbuk kering dari rimpangnya diseduh dengan segelas air panas, dinginkan lalu diminum sebagai obat batuk.

b. Satu lembar daun dipotong-potong kemudian direbus dengan tiga gelas air sampai tinggal bersisa satu gelas. Dinginkan lalu diminum untuk mengobati diabetes.

c. Satu lembar daun dikeringkan, lalu direbus dengan tiga gelas air hingga bersisa satu gelas, lalu diminum untuk obat ambeien.

\section{Ubi Kayu}

\section{Pemanfaatan}

Penyakit yang bisa diobati adalah rematik, luka, sakit kepala, diare, dan cacingan.

\section{Cara Penggunaan}

a. Haluskan 5 lembar daun singkong, $15 \mathrm{~g}$ jahe merah, kapur sirih, dan air secukupnya kemudin diaduk dan dioleskan pada bagian tubuh yang sakit rematik.

b. Tumbuk daun singkong, lalu digunakan untuk kompres sakit kepala.

c. Tumbuk singkong segar, lalu ditempelkan pada bagian tubuh yang luka bernanah.

d. Rebus 7 lembar daun singkong dengan $800 \mathrm{cc}$ air hingga tersisa 400 cc. selanjutnya, disaring dan diminum airnya sebanyak 200 cc untuk yang menderita diare.

e. Rebus $60 \mathrm{~g}$ kulit singkong dan $30 \mathrm{~g}$ daun ketepeng cina dengan $600 \mathrm{cc}$ hingga tersisa $300 \mathrm{cc}$. Selanjutnya, disaring dan diminum airnya menjelang tidur untuk penderita cacingan.

\section{Cabai Rawit \\ Pemanfaatan}

Tanaman cabai rawit bermanfaat untuk mempercepat metabolisme tubuh, membantu fungsi jantung, membantu pertumbuhan rambut, meringankan rasa nyeri, menurunkan berat badan, sakit tenggorokan, darah tinggi, sembuhkan infeksi, mencegah kanker, bisul, sakit perut, mengobati sakit beri-beri, habis bersalin.

\section{Cara Penggunaan}

a. Konsumsi langsung cabai atau campur dalam sayuran.

b. Oleskan cabai rawit pada kulit kepala akan meningkatkan sirpulasi darah sehingga dapat membantu pertumbuhan rambut.

c. Campurkan cabai rawit dengan air dan gunakan untuk berkumur. Berfungsi untuk membantu memulihkan sakit tenggorokan dengan cepat.

d. Cuci daun muda segar secukupnya, lalu giling sampai halus. Kemudian balurkan ke perut yang sakit atau balurkan ke bagian yang terkena bisul.

e. Daun atau batang (secukupnya) direbus kemudian airnya di minum untuk mengobati beri-beri.

f. Daun sebanyak 1 genggam ditumbuk dan dioleskan di bagian perut untuk ibu yang habis bersalin.

\section{Teratai Putih \\ Pemanfaatan}

Tanaman teratai bisa mengobati batuk darah, mengatasi diare disertai muntah, disentri, menormalkan tekanan darah, 
mengobati mimisan,menghilangkan insomnia, mengobati panas dalam, mengatasi bengkak dan iritasi, menghilangkan stress.

\section{Cara Penggunaan}

a. Bagian rimpang dari teratai di campur air matang 200cc di olah menjadi jus. Minum jus rimpang teratai secara rutin minimal tiga kali sehari, maksimal lima hari sehari. Untuk mengobati batuk darah.

b. 50 gram rimpang teratai ditambahkan dengan 10 gram rimpang jahe dicuci bersih, kemudian diolah menjadi jus. Lalu di saring dan minum air jus nya sebanyak 3 kali sehari. Untuk mengatasi diare disertai muntah.

c. Ambil 50 gram rimpang teratai, siapkan 10 gram jahe yang di parut kemudian di peras. Tambahkan air 100 cc dan rebus sampai mendidih. Setelah dingin, campurkan 1 sendok madu agar sedikit manis. Aduk sampai rata. Untuk mengobati disentri.

d. Ambil 10 gram biji teratai dan 15 gram tunas teratai campurkan dengan $350 \mathrm{cc}$ air bersih, rebushingga tersisa 200 cc saja. Minum air rebusannya secara teratur. Untuk menormalkan tekanan darah.

e. Ambil akar teratai di olah menjadi jus, Kemudian saring air jus nya, teteskan sedikit demi sedikit air jus tersebut ke dalam hidung. Untuk mengobati Mimisan

f. Ambil 12 gram biji bunga teratai, dan rendam selama 30 menit. Kemudian rebus menggunakan 3 gelas air, saat perebusan sisa kan hanya satu gelas saja. Kemudian minum air nya dan makan biji nya. Untuk menghilangkan insomnia

g. Siapkan 100 gram rimpang teratai dalam keadaan bersih dan 50 gram alang-alang, rebus semua bahan dengan $500 \mathrm{cc}$ air bersih hingga tersisa 250 cc saja. Saring dan minum air rebusan nya. Untuk mengobati panas dalam.

h. Ambil 3 gram biji teratai dan 9 gram bunga seruni di tampung menggunakan kain bersih. Kukus bahan tersebut selama 30 menit saat agak dingin kompres bagian yang bengkak dan iritasi. Lakukan dua kali sehari, pagi dan malam.

i. 20 butir biji teratai, 15 gram biji kelengkeng, 10 butir buah angcao, 10 gram kimcim, rebus semua bahan menggunakan $600 \mathrm{cc}$ air hingga tersisa menjadi $300 \mathrm{cc}$. Kemudian minum air rebusan nya. Untuk menghilangkan stress.

\section{Nanas}

\section{Pemanfaatan}

Penyakit yang bisa diobati adalah antiradang, membantu melunakan makanan di lambung, serta menghambat pertumbuhan sel kanker.Kandungan seratnya dapat mempermudah buang air besar pada penderita sembelit.

\section{Cara Penggunaan}

Buah langsung dimakan.

\section{Pokok Lipan}

\section{Pemanfaatan}

Penyakit yang bisa diobati adalah luka,bisul, koreng, dan penawar racun.

\section{Cara Penggunaan}

a. Daun dan batan dapat mengobati luka karena terpotong 
b. Oleskan getah pada penyakit kulit, penwar racun lipan atau kalajengking

\section{Meniran}

\section{Pemanfaatan}

Penyakit yang bisa diobati yaitu radang ginjal, susah kencing atau disertai sakit perut dan pinggang, batu ginjal, disentri, hepatitis, rabun senja, biul dikelopak mata, rematik, di gigit anjing, epilepsi.

\section{Cara Penggunaan}

a. Mengobati batu ginjal. Siapkan 1 sendok bubur daun kumis kucing, 7 batang tanaman meniran lengkap dengan akarnya. Semua bahan direbus kedalam 2 gelas air hingga menjadi 1 gelas. Air rebusan diminum sehari 3 kali sebanyak $1 / 2$ gelas.

b. Mengobati radang ginjal. Daun meniran sebanyak setengah genggam ditambah 3 gelas air, direbus sampai menjadi tiga per empatnya. Lalu ditambah madu. Diminum sehari 3 kali sebanyak $3 / 4$ gelas.

c. Mengobati susah kencing atau disertai sakit perut dan pinggang. Tanaman meniran sebanyak 7 gram, direbus dengan 2 gelas air sampai menjadi 1 gelas. Air rebusan diminum sebanyak $1 / 3$ gelas.

d. Mengobati disentri, rematik, dan hepatitis. Tanaman meniran segar sebanyak 30-60 gram direbus. Air rebusan diminm sehari sekali.

e. Mengobati rabun senja. Tanaman meniran yang segar sebanyak 15-20 gram ditambah hati ayam, lalu ditim. Dimakan bersama dengan makan pagi. f. Mengobati bisul dikelopak mata. Air rebusan meniran dipakai untuk mencuci mata.

g. Mengobati digigit anjing. Tanaman meniran yang segar sebanyak 4-6 gram direbus, lalu air rebusan diminum. Tempeli luka dengan tanaman meniran yang telah digiling halus dicampur nasi.

h. Mengobati epilepsi. Daun meniran sebanyak 3/4 genggam, direbus dengan sebanyak 5 gelas sampai tinggal setengahnya. Minum 3 kali sehari sebanyak $3 / 4$ gelas.

\section{Tebu}

\section{Pemanfaatan}

Mengobati jantung berdebar, sakit panas, batuk, kolesterol, patah tulang, stroke, penyakit kuning, menambah kekuatan (jantung, ginjal, liver), kanker paru-paru, tumor dan dapat menyembuhkan luka.

\section{Cara Penggunaan}

a. Kunyah tebu segar atau peras airnya lalu diminum.

b. Pakai ampas tebu untuk menutup luka dan menbebat patah tulang.

\section{Lengkuas}

\section{Pemanfaatan}

Digunakan sebagai tonikum, untuk menjaga stamina pria, anti jamur (Panu), meredakan rasa nyeri dan melindungi sel-sel tubuh dari agen berbahaya.

\section{Cara Penggunaan}

a. Tumbuk lengkuas, bawang putih, merica dan biji kedawung sampai halus. Setelah halus, campur semua bahan dengan asam jawa. Masak sampai mendidih, tambahkan gula 
dan garam secukupnya, peras dan saring kemudian di minum.

b. Iris melintang rimpang dan cacah. Hasil cacahan ditetesi minyak tanah setelah itu di gosokkan pada kulit yang terkena jamur.

\section{Lidah Buaya}

Pemanfaatan

Digunakan sebagai penyubur rambut/penghitam rambut, luka bakar, bisul, kencing manis, batuk rejan, dan sembelit.

\section{Cara Penggunaan}

a. Bagian dalam daun lidah buaya digosokkan ke kulit kepala untuk penyubur rambut.

b. Bagian dalam daun lidah buaya dapat di tempelkan pada bagian tubuh yang luka ringan akibat terbakar dan tersiram air panas.

c. Daun lidah buaya yang segar dihaluskan kemudian ditambah sedikit garam, tempelkan pada bisul.

d. Lidah buaya dipotong-potong seperlunya kemudian direbus. Air rebusan diminum setelah makan untuk mengobati kencing manis.

e. Daun segar $15-18 \mathrm{~cm}$, direbus ditambah gula diminum untuk mengobati batuk rejan.

\section{Lada}

\section{Pemanfaatan}

Penyakit yang bisa diobati adalah asma, mencret, masuk angin.

\section{Cara Penggunaan}

Seduh satu sendok makan bubuk lada dengan 2 gelas air panas. Setelah diaduk, saat hangat diminum dua kali sehari sampai penyakit asma, mencret, dan masuk angin dapat sembuh.

\section{Pandan}

\section{Pemanfaatan}

Penyakit yang bisa diobati adalah rematik dan pegal linu, lemah saraf, penenang atau mengatasi gelisah, juga berguna untuk menghilangkan ketombe dan menghitamkan rambut.

Cara Penggunaan (Hidayat dan Napitupulu, 2015)

a. Iris tipis daun pandan sebanyak 4 lembar, seduh dengan $1 / 2$ cangkir minyak kelapa yang dipanaskan sambil diaduk agar merata. Setelah dingin, gosokkan pada bagian tubuh yang rematik dan pegal linu.

b. Potong kecil-kecil daun pandan sebanyak 3 lembar lalu direbus dengan air 2 gelas sehingga tersisa 1 gelas. Setelah dingin, saring lalu diminum sebagai ramuan lemah saraf.

c. Iris tipis daun pandan dan seduh dengan segelas air panas. Setelah dingin saring lalu minum sebanyak 2 - 3 kali sehari sebagai obat penenang atau mengatasi gelisah.

d. Daun (secukupnya) ditumbuk halus kemudian diperas dan airnya dioleskan pada bagian rambut yang berketombe.

e. Rebusan daun yang didiamkan selama satu hari ditambah air perasan buah mengkudu dan gunakan campuran tersebut seperti sampo untuk menghitamkan rambut

\section{KESIMPULAN}

Tumbuhan bawah yang berkhasiat obat di kawasan Arboretum Sylva Indonesia Universitas Tanjungpura sebanyak 23 jenis yang tergolong ke dalam 19 famili. Tumbuhan bawah yang berkhasita obat meliputi Imperata 
cylindrica, Asplenium nidus, Lophatherum gracile, Stenochlaena palustris, Piper aduncum Lim, Melastoma malabathricum, Mimosa pudica, Ageratum conyzoides, Pyrrosia piloselloides, Justicia gendarussa, Cordyline fruiticosa, Sansevieria trifasciata, Manihot esculenta, Capsicum frutescens, Nymphaea alba, Ananas comosus, Euphorbia tithymaloides, Phyllanthus urinaria, Saccharum officinarum, Alpinia galanga, Aloe vera, Piper ningrum dan Pandanus amaryllifolius.

\section{SARAN}

Pentingnya usaha untuk menjaga dan mempertahankan kelestarian sumber daya alam yang ada pada kawasan Arboretum Sylva Indonesia PC. UNTAN khususnya jenis-jenis tumbuhan bawah yang berkhasiat obat, maka diharap kanpada seluruh instansi terkait agar dapat memberikan perhatian yang sungguh-sungguh terhadap pelestarian sumber daya alam ini.
DAFTAR PUSTAKA

Ambriansyah. 2010. Teknik Pengenalan Jenis dan Pembuatan Herbarium. Samboja. Kalimantan Timur.

Departemen Kesehatan Republik Indonesia, definisi tanaman obat Indonesia tercantum dalam SK Menkes

No.149/SK/Menkes/IV/1978

Rugayah, A. Retnowati, F.I. Windadari \& Hidayat. 2004. Pengumpulan Data Taksonomi. Dalam Rugayah, Elizabeth A, Widjaja, Praptiwi. Pedoman Pengumpulan Data Keanekaragaman Flora. Pusat Penelitian Biologi - LIPI. Bogor.

Hidayat, S dan Napitupulu, RM. 2015. Kitab Tumbuhan Obat. Penerbit Agrifio (Penebar Swadaya Group). Jakarta.

Wijayakusuma H.M.H, Dalimartha S dan Wirian A.S. 1993. Tanaman Berkhasiat Obat di Indonesia. Jilid II, Pustaka Kartini, Jakarta. 